\title{
A novel negevirus isolated from Aedes vexans mosquitoes in Finland
}

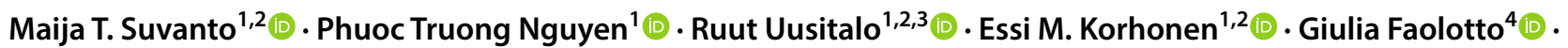 \\ Olli Vapalahti ${ }^{1,2,5} \cdot$ Eili Huhtamo $^{1,2}$ (D) Teemu Smura $^{1,5}$ (D)
}

Received: 23 June 2020 / Accepted: 13 August 2020 / Published online: 20 September 2020

(c) The Author(s) 2020

\begin{abstract}
Negeviruses are insect-specific enveloped RNA viruses that have been detected in mosquitoes and sandflies from various geographical locations. Here, we describe a new negevirus from Northern Europe, isolated from pool of Aedes vexans mosquitoes collected in Finland, designated as Mekrijärvi negevirus (MEJNV). MEJNV had a typical negevirus genome organization, is 9,740 nucleotides in length, and has a GC content of $47.53 \%$. The MEJNV genome contains three ORFs, each containing the following identified conserved domains: ORF1 (7,068 nt) encodes a viral methyltransferase, an FtsJlike methyltransferase, a viral RNA helicase, and an RNA-dependent RNA polymerase, ORF2 (1,242 nt) encodes a putative virion glycoprotein, and ORF3 (660 nt) encodes a putative virion membrane protein. A distinctive feature relative to other currently known negeviruses is a 7-nucleotide-long overlap between ORF1 and ORF2. MEJNV shares the highest sequence identity with Ying Kou virus from China, with $67.71 \%$ nucleotide and $75.19 \%$ and $59.00 \%$ amino acid sequence identity in ORF 1 and ORF 2, respectively. ORF3 had the highest amino acid sequence similarity to Daeseongdong virus 1 and negevirus Nona 1, both with $77.61 \%$ identity, and to Ying Kou virus, with $71.22 \%$ identity. MEJNV is currently the northernmost negevirus described. Our report supports the view that negeviruses are a globally distributed, diverse group of viruses that can be found from mosquitoes in a wide range of terrestrial biomes from tropical to boreal forests.
\end{abstract}

Negeviruses are positive-sense single-stranded enveloped RNA viruses of insects. They have been isolated from mosquitoes of various genera (e.g., Culex, Aedes, Anopheles, and Psorophora) and from Lutzomyia sandflies around the world, including the Americas, Africa, Middle East, Europe, Asia, and Australia [1-6]. Negeviruses have 9- to 10-kb genomes that contain three open reading frames (ORFs). ORF1 encodes a methyltransferase, an FTsJ-like helicase, a viral

Handling Editor: T. K. Frey.

Maija T. Suvanto

maija.t.suvanto@helsinki.fi

1 Department of Virology, Medicum, University of Helsinki, Helsinki, Finland

2 Department of Veterinary Biosciences, University of Helsinki, Helsinki, Finland

3 Department of Geosciences and Geography, University of Helsinki, Helsinki, Finland

4 Laboratory of Microbiology and Virology, University Hospital Maggiore Della Carità Di Novara, Piemonte, Novara, Italy

5 Department of Virology and Immunology, Helsinki University Hospital, HUSLAB, Helsinki, Finland
RNA helicase, and an RNA-dependent RNA polymerase (RdRp), ORF2 encodes glycoproteins, and ORF3 encodes virion membrane proteins [1-3]. The recently proposed "Negevirus" taxon consists of two clades, named "Nelorpivirus" and "Sandewavirus" [3, 5], and the taxon is related to plant viruses of the genera Cilevirus, Higrevirus and Blunervirus [1, 7]. In recent years, the "Negevirus" taxon has been expanding with several new negeviruses being reported. The geographical origins of mosquito-associated negeviruses include various terrestrial biomes, mainly temperate, subtropical, and tropical forest areas. Here, we report a novel negevirus isolated from Aedes vexans mosquitoes from a boreal coniferous forest area in Finland.

Mosquitoes were collected for an arbovirus study in August 2018 in Mekrijärvi (62 $\left.45^{\prime} 43^{\prime \prime} \mathrm{N}, 30^{\circ} 57^{\prime} 32^{\prime \prime} \mathrm{E}\right)$, Eastern Finland [8]. One mosquito pool consisting of 26 individual female mosquitoes caused a strong cytopathic effect (CPE) in Aedes albopictus C6/36 cells. The voucher specimen for this mosquito pool was identified morphologically [9] as Aedes vexans. RNA was extracted from virus isolation supernatant collected 10 days after infection, using TRIzol Reagent (Thermo Fisher). A sequencing library was prepared using an NEBNext Ultra II RNA Library Prep 
Kit (New England Biolabs), quantified using an NEBNext Library Quant Kit for Illumina (New England Biolabs), and sequenced on a MiSeq platform using a MiSeq Reagent Kit v2 with 150-bp paired-end reads. Raw sequence reads were trimmed, and low-quality (quality score $<30$ ) and short $(<50 \mathrm{nt})$ sequences were removed using Trimmomatic [10]. Thereafter, de novo-assembly was conducted using MegaHit, followed by re-assembly against the de novo assembled consensus sequence using the BWA-MEM algorithm [11] implemented in SAMTools version 1.8 [12]. A total of 357,745 reads mapped to the largest contig, with mean coverage of 7,624 (range, 146-17,546).

A genomic sequence of $9,740 \mathrm{nt}$ was identified as a negevirus using an NCBI BLASTx search, and the isolate was designated as "Mekrijärvi negevirus" (MEJNV) (GenBank accession number MT522375). Three ORFs were identified in the MEJNV genome using NCBI ORFfinder (https://www.ncbi.nlm.nih.gov/orffinder/) (Fig. 1), flanked by untranslated regions (unverified) of $509 \mathrm{nt}$ (5'UTR) and $162 \mathrm{nt}$ (3'UTR) in length. MEJNV was most similar to Ying Kou virus strain YK1714 (NC_040636.1) originating from Culex pipiens pallens mosquitoes in China, with $67.71 \%$ nucleotide sequence identity. The genome size and the detected ORFs were similar, and the GC content (GC\%) of $47.53 \%$ was slightly higher when compared to previously described negeviruses (avg. GC\% $=41.11 \%$ ). The 3'terminus of ORF1 and the 5 'terminus of ORF2 were found to overlap by seven nucleotides, and this is a distinct feature of the MEJNV genome. Conserved protein domains were identified using NCBI CD-search (https://www.ncbi.nlm.nih.gov/ Structure/cdd/wrpsb.cgi) (Fig. 1). The identified domains and their positions within the ORFs align with those of previously described negeviruses [1] (Fig. 1). The evolutionary relationship of MEJNV to other related negeviruses was assessed by constructing a phylogenetic tree based on ORF1 amino acid sequences of negevirus strains ( $n=43$ ). The database sequences were aligned using MAFFT version 7.453 [13] and used to compute a midpoint-rooted maximumlikelihood tree with 1,000 bootstrap replicates in IQ-TREE version 1.6.12 [14], using the ModelFinder [15] and ultrafast bootstrap [16] algorithms (Fig. 2). ModelFinder suggested $\mathrm{LG}+\mathrm{F}+\mathrm{R} 10$ as the optimal substitution model. The final tree was visualized with FigTree version 1.4.4 (https ://tree.bio.ed.ac.uk/software/figtree/). Nucleotide sequence alignments done with MAFFT showed the highest similarity between MEJNV and Ying Kou virus (NC_040636.1) from China, with $67.71 \%$ nucleotide sequence identity. Similar analysis done with amino acid sequences showed $75.19 \%$ identity between ORF1, 59.00\% between ORF2, and 71.22\% between ORF3 sequences. However, the closest matches to ORF3 of MEJNV were those of Daeseongdong virus 1 (NC_028487.1) and negevirus Nona 1 (AB972669.1), both with $77.61 \%$ identity. Notably, the GC\% of MEJNV was similar to that of Ying Kou virus $(\mathrm{GC} \%=48.18 \%)$. Phylogenetic analysis suggested that MEJNV forms a monophyletic cluster (bootstrap value, 100) with Ying Kou virus. The closest relatives of MEJNV and Ying Kou viruses included viruses from Japan and South Korea (Daeseongdong virus 1 and negevirus Nona 1) and more distant relatives from South America, Australia, and the Philippines. Notably, the geographically closest negevirus sequence from Sweden in 2009 (Biggie virus, GenBank accession no. QGA70894) was not grouped with MEJNV. These results indicate that MEJNV is a distinct strain of negevirus related to negeviruses from distant geographical locations, and it is currently the northernmost negevirus strain to be isolated. Our results support the view that negeviruses are distributed globally in mosquitoes.

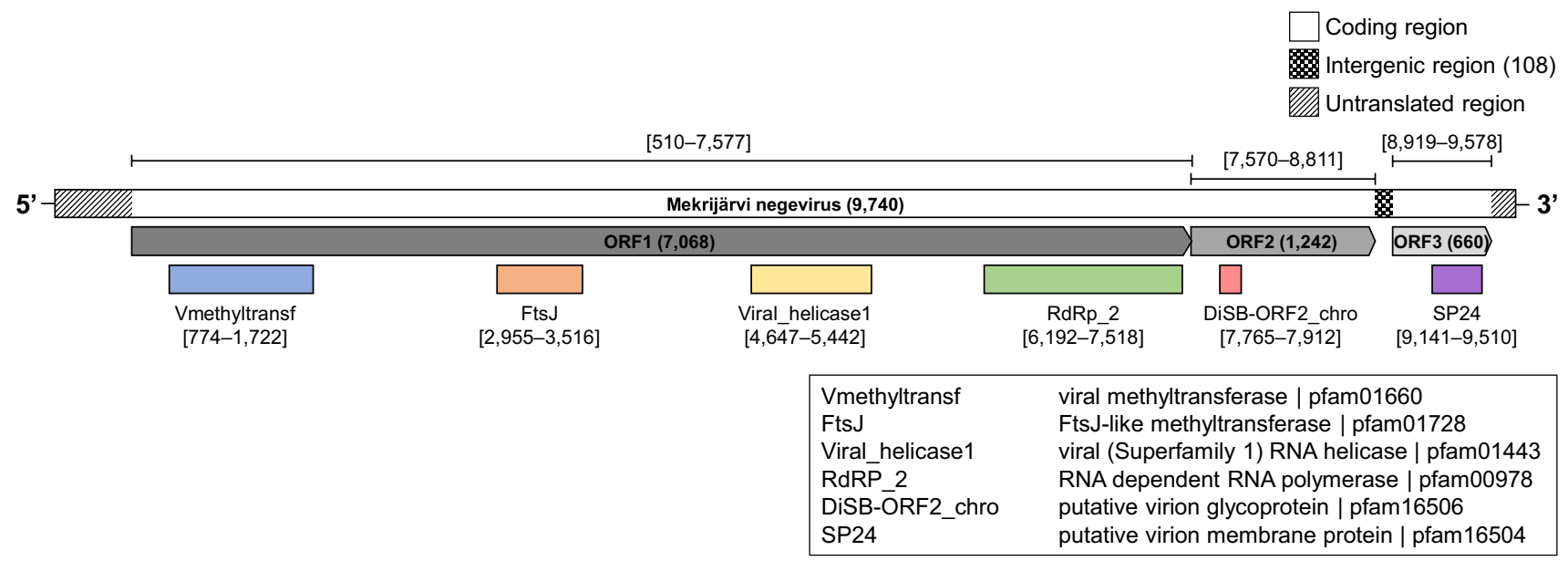

Fig. 1 Genome organization of the novel Mekrijärvi negevirus. The lengths (in nucleotides) of ORFs 1-3 and the intergenic region are shown in parentheses. The nucleotide positions of ORFs and their putative conserved protein domains within the genome are shown in square brackets 


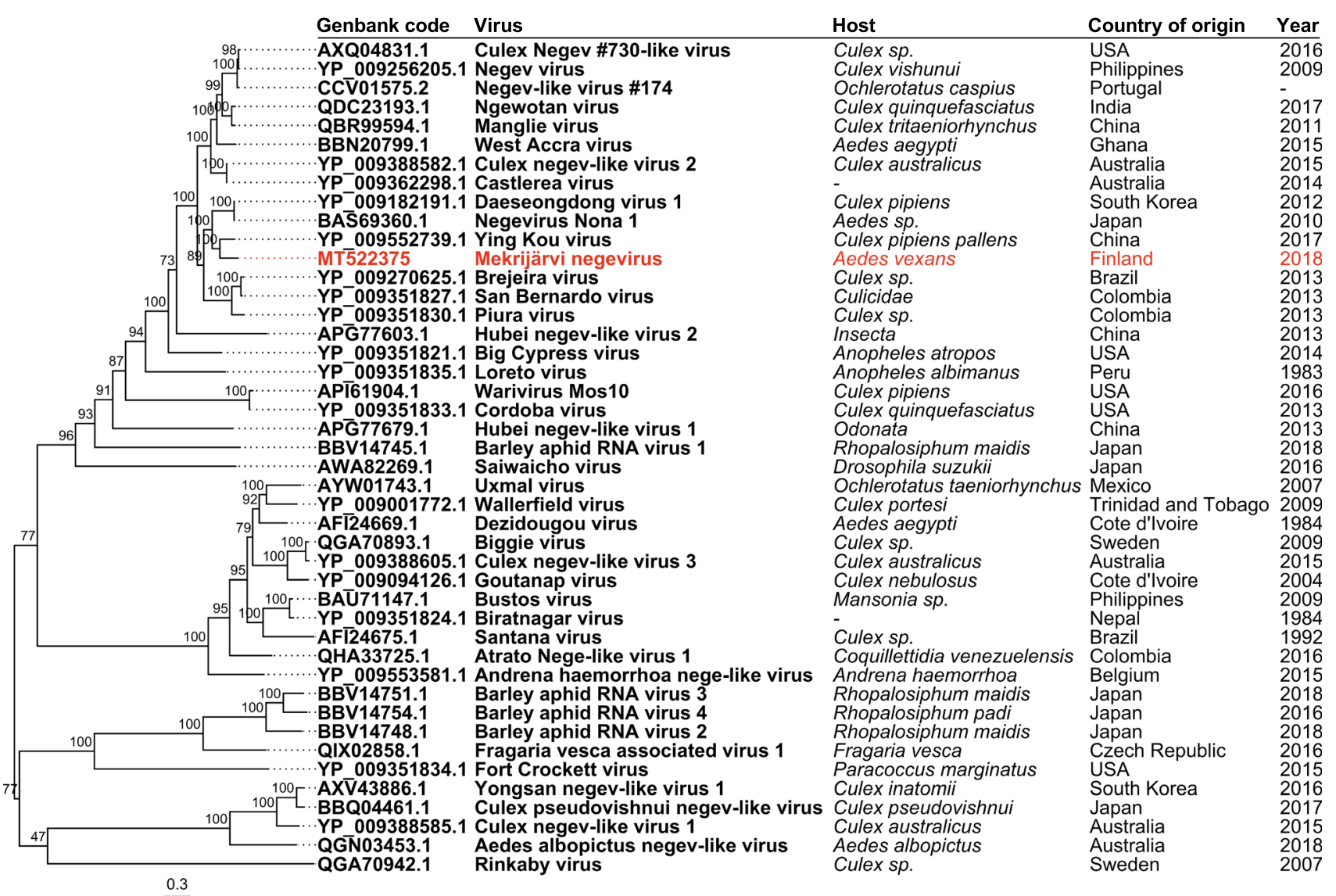

Fig. 2 Phylogenetic tree of negeviruses and related viruses $(n=43)$ computed from protein sequences of ORF1 containing the RNAdependent RNA polymerase (RdRp). The host, country of origin, and collection year are shown in square brackets. Unknown information is indicated by a hyphen. Sequences were aligned using MAFFT, and a maximum-likelihood tree with 1,000 bootstrap replicates was built using IQ-TREE. The tree is rooted at the midpoint
Acknowledgements We would like to thank Megrin Matkailu Oy for providing facilities during fieldwork. We acknowledge CSC-IT Center for Science Ltd. (Espoo, Finland) for the allocation of computational resources.

Funding Open access funding provided by University of Helsinki including Helsinki University Central Hospital. This study was supported by grants from the Jane and Aatos Erkko Foundation, the Sigrid Jusélius Foundation, the Academy of Finland, the University of Helsinki Doctoral Programme in Interdisciplinary Environmental Sciences (DENVI), the Paulo Foundation and the Finnish Cultural Foundation the Kymenlaakso Regional Fund.

\section{Compliance with ethical standards}

Conflict of interest The authors declare no conflict of interest.
Availability of data and material The Mekrijärvi negevirus genome sequence has been deposited in the NCBI GenBank database under accession number MT522375.

Open Access This article is licensed under a Creative Commons Attribution 4.0 International License, which permits use, sharing, adaptation, distribution and reproduction in any medium or format, as long as you give appropriate credit to the original author(s) and the source, provide a link to the Creative Commons licence, and indicate if changes were made. The images or other third party material in this article are included in the article's Creative Commons licence, unless indicated otherwise in a credit line to the material. If material is not included in the article's Creative Commons licence and your intended use is not permitted by statutory regulation or exceeds the permitted use, you will need to obtain permission directly from the copyright holder. To view a copy of this licence, visit http://creativecommons.org/licenses/by/4.0/. 


\section{References}

1. Vasilakis N, Forrester NL, Palacios G, Nasar F, Savji N, Rossi SL, Guzman H, Wood TG, Popov V, Gorchakov R, Gonzalez AV, Haddow AD, Watts DM, da Rosa APAT, Weaver SC, Lipkin WI, Tesh RB (2013) Negevirus: a proposed new taxon of insect-specific viruses with wide geographic distribution. J Virol 87(5):2475-2488. https://doi.org/10.1128/jvi.00776-12

2. O'Brien CA, McLean BJ, Colmant AMG, Harrison JJ, Hall-Mendelin S, van den Hurk AF, Johansen CA, Watterson D, BielefeldtOhmann H, Newton ND, Schulz BL, Hall RA, Hobson-Peters J (2017) Discovery and characterisation of castlerea virus, a new species of Negevirus isolated in Australia. Evolut Bioinform 13:10-12. https://doi.org/10.1177/1176934317691269

3. Nunes MRT, Contreras-Gutierrez MA, Guzman H, Martins LC, Barbirato MF, Savit C, Balta V, Uribe S, Vivero R, Suaza JD, Oliveira H, Nunes Neto JP, Carvalho VL, da Silva SP, Cardoso JF, de Oliveira RS, da Silva Lemos P, Wood TG, Widen SG, Vasconcelos PFC, Fish D, Vasilakis N, Tesh RB (2017) Genetic characterization, molecular epidemiology, and phylogenetic relationships of insect-specific viruses in the taxon Negevirus. Virology 504:152-167. https://doi.org/10.1016/j.virol.2017.01.022

4. Carapeta S, do Bem B, McGuinness J, Esteves A, Abecasis A, Lopes Â, de Matos AP, Piedade J, de Almeida APG, Parreira R (2015) Negeviruses found in multiple species of mosquitoes from southern Portugal: isolation, genetic diversity, and replication in insect cell culture. Virology 483:318-328. https://doi. org/10.1016/j.virol.2015.04.021

5. Kallies R, Kopp A, Zirkel F, Estrada A, Gillespie TR, Drosten C, Junglen S (2014) Genetic characterization of goutanap virus, a novel virus related to negeviruses, cileviruses and higreviruses. Viruses 6(11):4346-4357. https://doi.org/10.3390/v6114346

6. Zhao L, Mwaliko C, Atoni E, Wang Y, Zhang Y, Zhan J, Hu X, Xia H, Yuan Z (2019) Characterization of a novel tanay virus isolated from anopheles sinensis mosquitoes in Yunnan, China. Front Microbiol 10:1-11. https://doi.org/10.3389/fmicb.2019.01963

7. Charles J, Tangudu CS, Hurt SL, Tumescheit C, Firth AE, Garcia-Rejon JE, Machain-Williams C, Blitvich BJ (2018) Detection of novel and recognized RNA viruses in mosquitoes from the Yucatan Peninsula of Mexico using metagenomics and characterization of their in vitro host ranges. J Gen Virol 99(12):1729-1738. https://doi.org/10.1099/jgv.0.001165

8. Korhonen EM, Suvanto MT, Uusitalo R, Faolotto G, Smura T, Sane J, Vapalahti O, Huhtamo E (2020) Sindbis virus strains of divergent origin isolated from humans and mosquitoes during a recent outbreak in Finland. Vector-Borne Zoonotic Dis. https:// doi.org/10.1089/vbz.2019.2562

9. Becker N, Petric D, Zgomba M, Boase C et al (2010) Mosquitoes and their control. Springer, Berlin, Heidelberg

10. Bolger AM, Lohse M, Usadel B (2014) Trimmomatic: a flexible trimmer for Illumina sequence data. Bioinformatics 30(15):2114-2120

11. Li H (2013) Aligning sequence reads, clone sequences and assembly contigs with BWA-MEM. arXiv. 1303.3997v1

12. Li H, Handsaker B, Wysoker A, Fennell T, Ruan J, Homer N, Marth G, Abecasis G, Durbin R, Subgroup GPDP (2009) The sequence alignment/map format and SAMtools. Bioinformatics 25(16):2078-2079

13. Katoh K, Standley DM (2013) MAFFT multiple sequence alignment software version 7: improvements in performance and usability. Mol Biol Evol 30(4):772-780

14. Nguyen L-T, Schmidt HA, von Haeseler A, Minh BQ (2014) IQTREE: a fast and effective stochastic algorithm for estimating maximum-likelihood phylogenies. Mol Biol Evol 32(1):268-274

15. Kalyaanamoorthy S, Minh BQ, Wong TKF, von Haeseler A, Jermiin LS (2017) ModelFinder: fast model selection for accurate phylogenetic estimates. Nat Methods 14(6):587-589

16. Hoang DT, Chernomor O, von Haeseler A, Minh BQ, Vinh LS (2017) UFBoot2: improving the ultrafast bootstrap approximation. Mol Biol Evol 35(2):518-522

Publisher's Note Springer Nature remains neutral with regard to jurisdictional claims in published maps and institutional affiliations. 